\title{
Servitization of Machine-Tool Trading Company to Value Orchestration Platform: Visualization of Japanese Integral-Modular Strategies
}

\author{
Kazuhiko Goda', Kyoichi Kijima ${ }^{2}$ \\ ${ }^{1}$ Goda Shoji Co. Limited, Takamatsu, Japan \\ ${ }^{2}$ Graduate School of Decision Science and Technology, Tokyo Institute of Technology, Tokyo, Japan \\ Email: kazuhiko goda@godashoji.co.jp, Kijima@valdes.titech.ac.jp
}

Received 13 April 2015; accepted 12 June 2015; published 17 June 2015

Copyright (C) 2015 by authors and Scientific Research Publishing Inc.

This work is licensed under the Creative Commons Attribution International License (CC BY). http://creativecommons.org/licenses/by/4.0/

(c) (i)

\begin{abstract}
It is controversial whether or not Japanese manufacturing is already in decline and the Japanese model of manufacturing that drove past decades of the industrial and economic growth has lost the power. It is though true that Japan needs to develop a new and innovative business model for manufacturing in the years ahead. The present paper aims at (1) arguing that Japanese manufacturing requires transformation from integral-technology-based to modular-technology-based as well as their co-existence and (2) visualizing strategies for supporting them in practical terms. We in particular claim that in the transformation Machine-Tool Trading (MTT) companies should play a crucial role in getting servitizatized and functioning as project producers. We discuss roles and functions to be expected from servitized MTT companies by using the value orchestration platform model with quality control 7 tools as a reference. We also illustrate a roadmap for an MTT company to be servitized based on some real observations as well as the authors' experiences.
\end{abstract}

\section{Keywords}

Servitization, Value Orchestration Platform, Quality Control, Modular Business Model, Machine-Tool Trading Company

\section{Introduction}

\subsection{Next Strategies for Japanese Manufacturing: Research Background}

In recent years, media all over the world, referring to a large loss or a problem in the Japanese electronics indus-

How to cite this paper: Goda, K. and Kijima, K. (2015) Servitization of Machine-Tool Trading Company to Value Orchestration Platform: Visualization of Japanese Integral-Modular Strategies. Journal of Service Science and Management, 8, 349364. http://dx.doi.org/10.4236/jssm.2015.83037 
try, make comments that Japanese manufacturing is already in decline. In Japan there have been deep and long debates on the Japanese model of manufacturing that drove past decades of industrial and economic growth, especially on the architecture of its design information, products, and production phases.

[1] states that the on-site organizational capability of manufacturing in Japan ("monozukuri", manufacturing as a craft in Janpanese) is characterized by capability for creation and transmission of design information and refers to the basic characteristics of the design information as "architecture".

The architecture is classified in terms of the interdependence of component design, that is, the correspondence between the constituent functions and components of the product. Such design information that functions and components are interrelated in a complex manner is called "integral" architecture. If functions and components are in nearly one-to-one correspondence, the design information is called "modular" architecture. Architecture of an automobile is typically integral architecture, whereas a personal computer typifies modular architecture.

In automotive and other integral products, Japanese manufacturing continues to hold a leading position in global markets. In light electrical products, in contrast, it has fallen behind in the face of pervasive modularization of large-volume production that has accompanied the tremendous rise in global market volumes.

It is claimed that consistency between product architecture and organizational capability largely governs competitive strength [2]. In the past, Japanese companies thrived and grew by building their organizational capability for integration-based manufacturing that focused on operations and an integral architecture highly suited to their products. Most of the Japanese export products were integral products. In assembled products, in particular, the export ratio and international competitive strength tended to increase with the degree of integration and labor concentration. Japanese manufacturing was thus driven by integrated, operation-focused manufacturing sites.

The crucial and challenging task many manufacturers in Japan now face is to develop an innovative modular business model for co-existence of the traditional Japanese-style integration-based manufacturing that focused on operations and an integral architecture and the American-style concept-based strategy, to enhance the capability for strategy conceptualization at the manufacturing sites. To rebuild the manufacturing capability in this way it will be necessary to (1) strengthen teamwork of the long-term and multi-skilled workers, capability- building, high-productivity and high-wage mode to enhance domestic production of competitive-advantage inte- gral products; (2) build a new modular production system that is certainly modularized but also in correspondence with integral manufacturing for creation of Japan-specific high added value; and (3) educate and develop personnel and organizations' capability of creating and developing a corresponding strategic modular business model [1] [3].

Transformation strategies from integral technology to modular technology are essential for realizing these changes, but it is generally very difficult to visualize the internalized integral technology residing in highly skilled individuals and to extend it to modular technology. It will require long lead times, with no guarantee of success [3].

These arguments shed light on a new role of machine-tool trading companies (MTT companies). Serving as a project producer an MTT company (1) obtains the participation of machine-tool manufacturers and complementary companies (peripheral equipment manufacturers) with competitive advantages in planning and implementation, and (2) functions as a business architect (designer) to allocate, interlink, and modify the component work sectors [4]. Since an MTT company as a producer needs to view the target products as such a system that various functions, component products and services are integrated, collaborative value co-creation with the customers is essential for goal attainment [5].

To perform the new role, the MTT company is required to be servitized by innovating its capabilities and processes to better co-create value through a shift from selling product to selling product-service systems offering value-in-use [6]. We agree that a servitized MTT company must be capable to advance conceptualization, judgment and evaluation, and to form networks that transcend boundaries between industrial sectors [4].

\subsection{Research Purposes}

In the present paper we first show the significance of reconstructing an innovative modular business model for development and growth of Japanese manufacturing in the years ahead. We then claim that for supporting transformation from integral technology to modular technology and their co-existence in manufacturing, Machine-Tool Trading (MTT) companies should play a crucial role in getting sevitized and functioning as project producers who create high added value.

Next, we argue some concrete roles and functions to be expected from servitized MTT companies. As a ref- 
erence framework for analysis on the construction of this business model, we invoke the value orchestration platform model with quality control 7 tools. If the value orchestration platform functions effectively in transformation of the integral technology that has long characterized Japanese manufacturing to a modular configuration, in concert with advancement of veteran worker skill transmission to younger workers, it will realize manufacture of integral products using modular technology. It should also contribute to cost reductions, a high level of performance and establishment of geographically advantageous bases for domestic production of integral products.

Finally, we explicate the methodologies, prescriptions and strategies necessary for the implementation in practical terms and then illustrate a roadmap for a MTT company to be servitized based on some real observations as well as the authors' experiences. We also demonstrate how these strategies would contribute to the recovery of competitive strength and spur restoration of the competitive position of the Japanese manufacturing industry.

\section{Future Configuration of Japanese Manufacturing: Transformation from Integral to Modular Technology}

[4] introduces a well-known typology of products based on the characteristics of their architecture (Figure 1). The horizontal axis represents the degree of component design interdependence, from product integration (internal inter-adjustment) on the left to product modularization (assembly) on the right. The vertical axis represents the degree of linkage with other companies, from open (industrial standards-based) products at the bottom to closed (internalized) operation at the top.

Employing the typology, Fujimoto argues future configurations for Japanese manufacturing and proposes the "architecture portfolio strategies" as shown by Figure 1, where internal integral/external integral technology is called simply "integral technology", while internal modular/external integral technology is called "modular technology" [4].

Fujimoto suggests: (1) Shifting downward from upper-left position should be expected to yield cost reduction through transformation from internal to modular production technology in combination with customization by high-level assembly; (2) If products equivalent to integral products and components can be produced in this way, as though they were the result of integral production technology alone, it will contribute to cost reductions that effectively offset the high-wage, high-currency handicap of domestic factories and may effectively establish an internal- and external-integral combination [2].

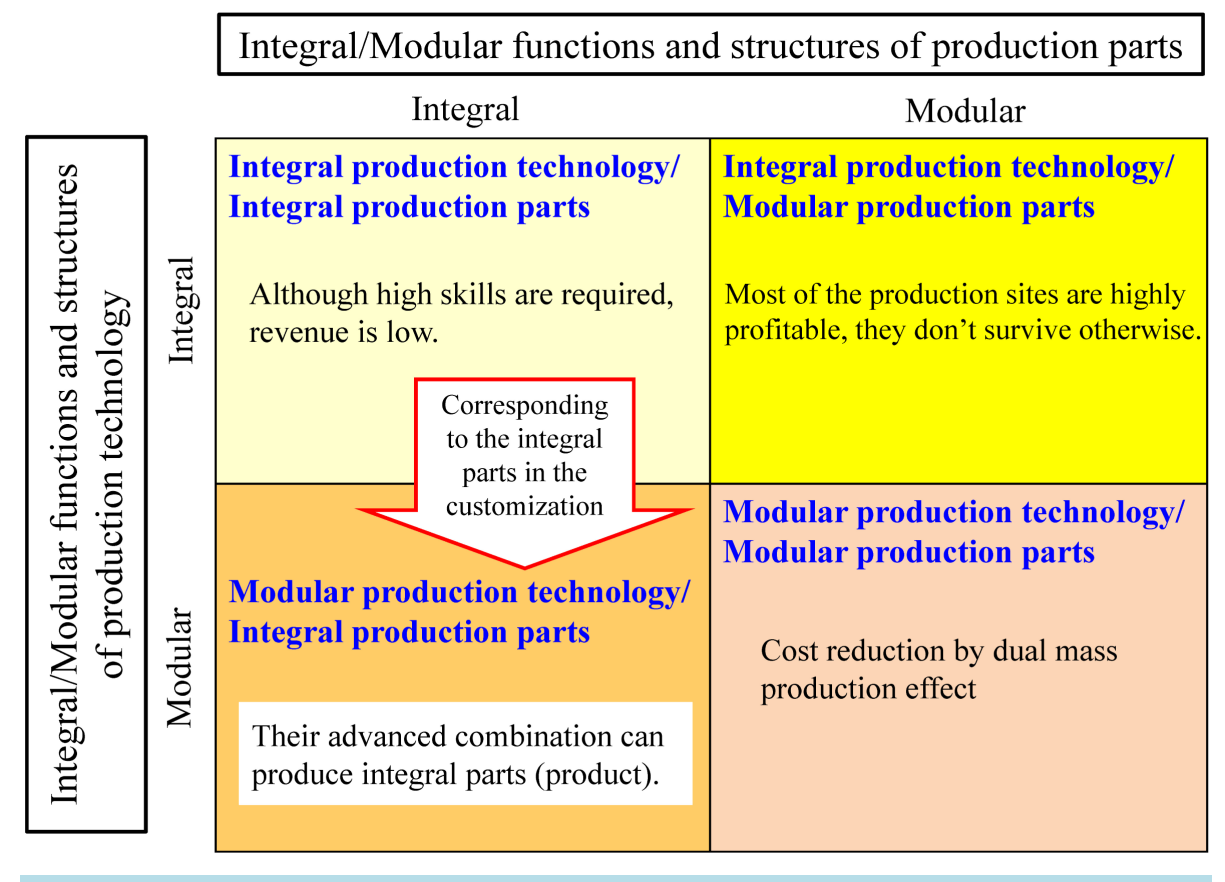

Figure 1. Architecture portfolio strategies (Based on [4]). 
Integral technology is generally an art that is dependent on the capability of individuals in what is known as "skill". Since the skill inheres in the individual, it is difficult to set forth in manuals and is both difficult and costly to transmit to others. In addition, this transmission is highly dependent on the ability of the individual. Thus, this skill is high in attenuation and low in communicability.

The capabilities required for achievement of integral technology and provided by veteran workers born during the "baby boom" period of the late 1940s (who are known as "the artisans") have long supported the rise of Japanese competitive strength, but the transmission of these skills to the younger generation is now confronted by a particularly grave difficulty. The Statistics Bureau of the Ministry of Internal Affairs and Communications has sounded an alarm in its report on "The 10-year problem (2007-2016) of baby boomer retirement” [7], with many veteran craftsmen scheduled to retire from their domestic manufacturing workplaces around 2016.

In modular technology, a key objective is to express skill in readily transmissible diagrams, equations, words, and other forms of objective, explicit knowledge, thereby facilitating its propagation and enabling its direct written input to machinery. The hand of the human craftsman has long been superior in accuracy and precision to that of machines. Recent technological advances have now brought machinery to an extremely high level of accuracy. This, together with the increasing modularization of machine-tool supplementary products (i.e., peripheral equipments) and assembly customization, now makes it possible to attain a level of modular technology equaling that of integral technology.

In developing the future configuration of Japanese manufacturing, comparative investigations to determine the combination required for modularization of integral technology would be impracticable because of the huge number of potential combinations involved. It is more realistic to apply a platform strategy in which new industrial clusters of intercompany linkages can emerge at the manufacturing site and thus within the factory, and in this way work toward the goal of modular transformation [3] [4] [8].

In the following sections, we point out that MTT companies can serve as a platform, enabling the emergence of a high-level modular production system and thereby accelerating the transmission of skills to young workers and contributing greatly to construction of Japanese manufacturing capabilities.

\section{Value Orchestration Platform Model: Reference Framework for MTT Company Analysis}

As a reference framework for analysis, we invoke the value orchestration platform model [9] and its discussion of value orchestration management, and explicate its methodology and prescription. More specifically, we attempt to show how a MTT company, serving as a platform, can participate in the four processes of value cocreation, effectively apply the three component strategies, and propose practical, effective tools in the form of prescriptions for this purpose.

The value orchestration platform model is a two-level service system model comprising the value co-creation process and the supporting platform [9] [10] (Figure 2). It especially characterizes business models of Knowledge-Intensive Business Services (KIBS) which is often based on ICT [11].

It first identifies four phases in value co-creation process, i.e., co-experience, co-definition, co-elevation and co-development phases. In the co-experience phase, in particular, "fan-making strategy" between the customer and provider is a key. For this purpose it is important in practical terms to operate the SIPS (Sympathy, Identification (Interest), Participation and Sharing) cycle as a positive feedback loop, thereby inducing both provider and customer to become repeaters [9] [12].

In the co-definition phase, on the other hand, the quality of the internal model explication and visualization will determine the effectiveness of subsequent value co-creation.

Co-elevation is a phase of needs-pull and seeds-push interaction between the customer and the provider. In sharing internal models with the customer, the provider generally tends to identify the customer's needs and expectations and attempt to meet them by raising its service provision capability. If this capability rises, the customer receiving the service tends to raise its receiving capability and expected service value incrementally, to a new level of needs and expected value. The co-elevation of service value proceeds through repetition of this interaction. The course of value co-elevation is characteristically discontinuous, as in a game of "playing catch", and proceeds in intervals between actual service provisions, thus taking on a zigzag, spiraling form in general.

Co-development refers to co-innovation of value by simultaneous collaboration among the various factors including customers and providers. 

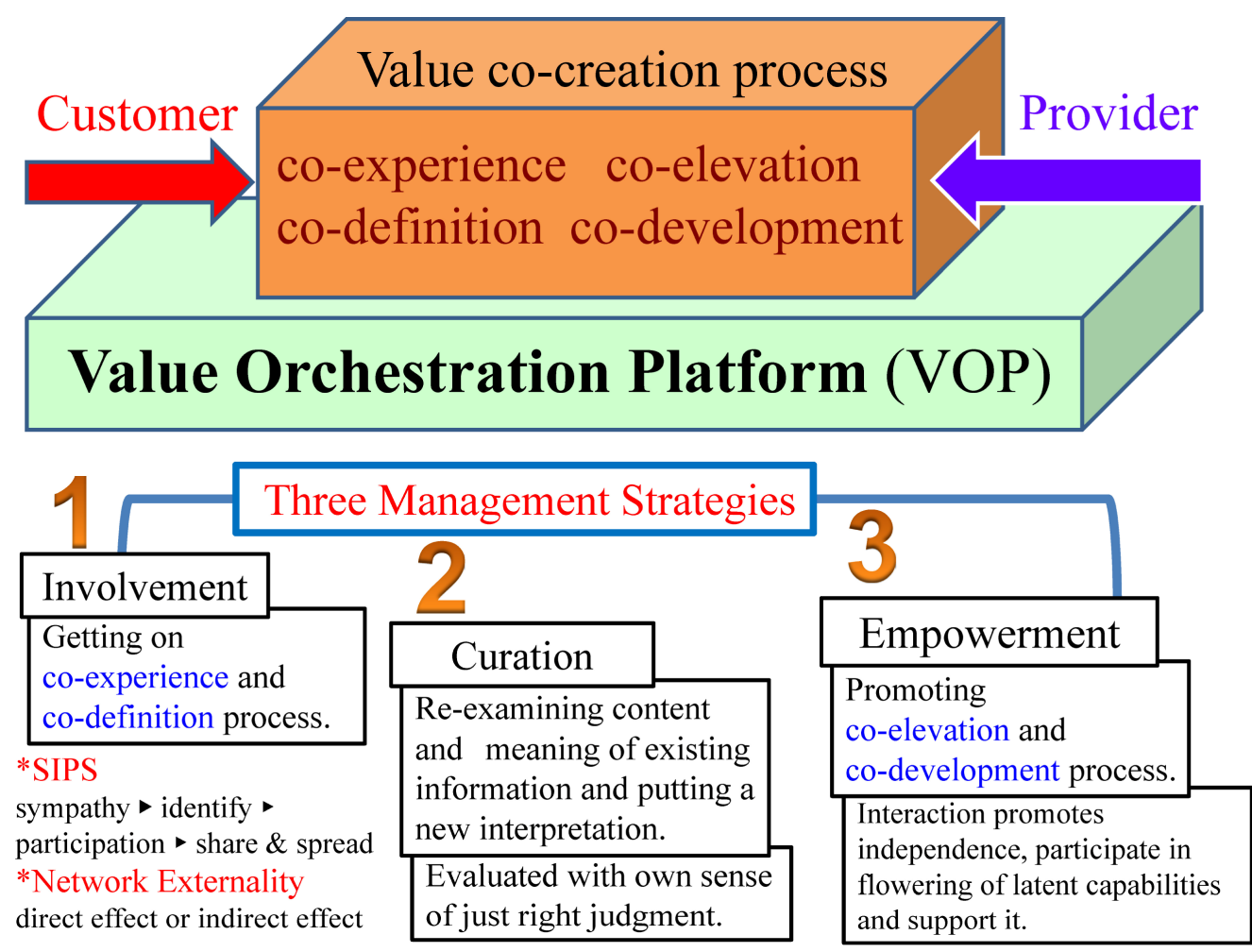

Figure 2. Value orchestration platform model [9] [10].

The chief interest of this platform model is examining the strategies for management and supporting of the four phases of value co-creation [13]. It also works as a checklist for value co-creation process management. The model proposes three strategies: involvement, curation, and empowerment strategies [9] [10] [14].

For co-experience and co-definition phases, the most important strategy the platform should take is to attract, invite and involve relevant actors onboard. We call it involvement strategy. For co-elevation and co-development phases, the platform needs to take such a highly proactive and selective approach: (1) It collects, selects, analyzes, edits and reexamines content and meaning of existing products, service and information on customers and providers in order to put a new interpretation on and give a new meaning to them; (2) Based on the newly developed interpretation and meaning, it facilitates value co-creation process involving customers, providers, information and technology. We call this strategy curation strategy.

The platform also needs to support the actors on the board to develop their capabilities as well as to level up aspiration level of the customers. We call this strategy empowerment strategy.

We will discuss these strategies in terms of MTT companies in the following sections.

\section{Value Orchestration Platform Strategies for MTT Companies}

\subsection{Transformation of MTT Company Business Model}

The traditional business model of MTT companies in Japan in effect generally restricts each MTT company to a single machine-tool manufacturer and to support of that company (Figure 3). It does not function as value orchestration platform for value co-creation. It portrays, rather, a world of price competition marked by exchanges of machine-tool specifications and estimates. The traditional business model is far removed from any sort of modular business model.

In its new configuration, the MTT company itself should be transformed to a value orchestration platform, bring a number of manufacturers and customers onboard, and employ strategies for their co-creation of value. Those to be brought aboard must total at least seven or eight companies which are independent entities, and include brand manufacturers and suppliers as customers and machine-tool, cutting-tool, holder, jig, materialshandling (robots), CAD/CAM, and production-material manufacturers as providers (Figure 4). 


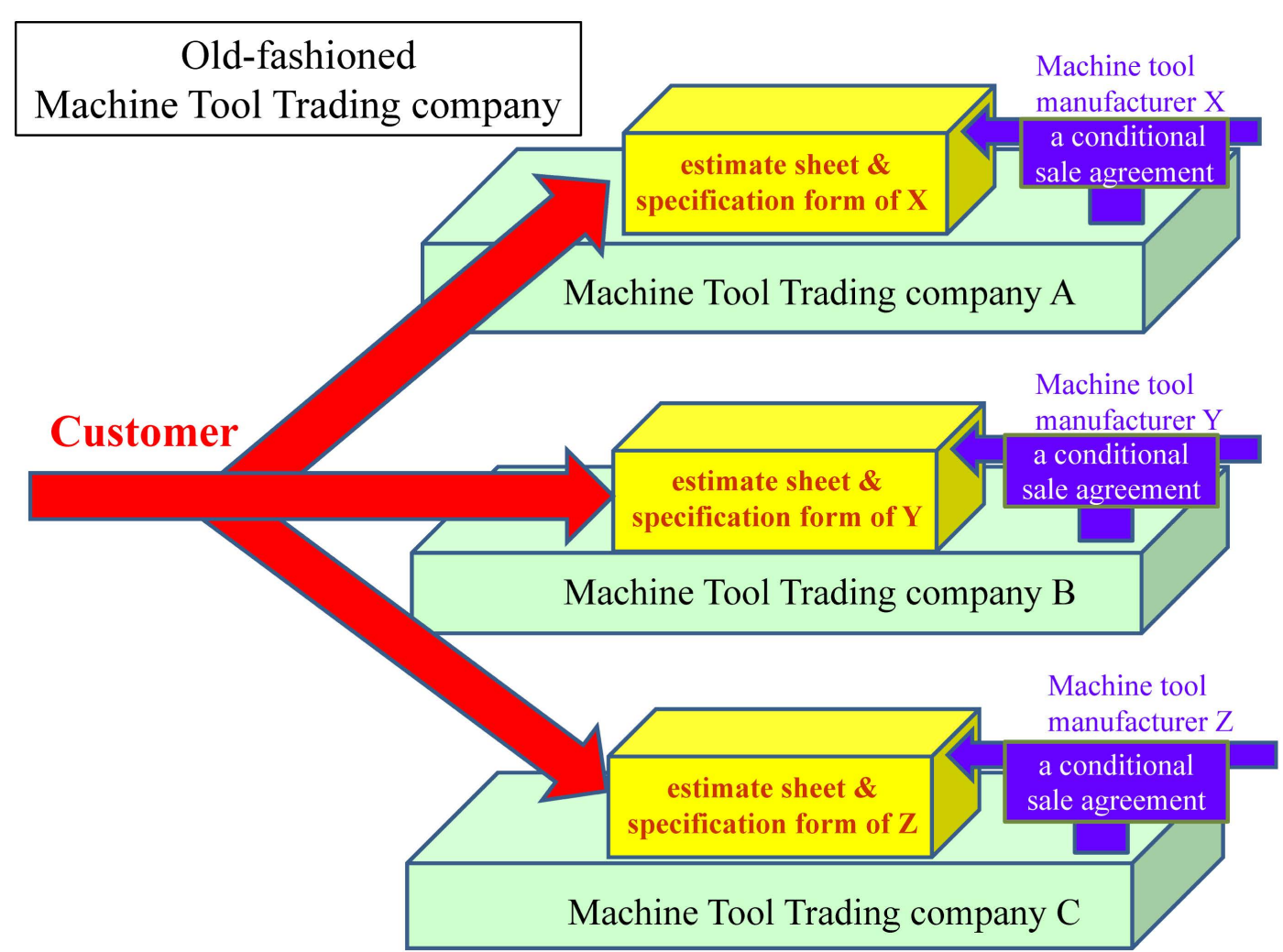

Figure 3. Old-fashioned MTT company.

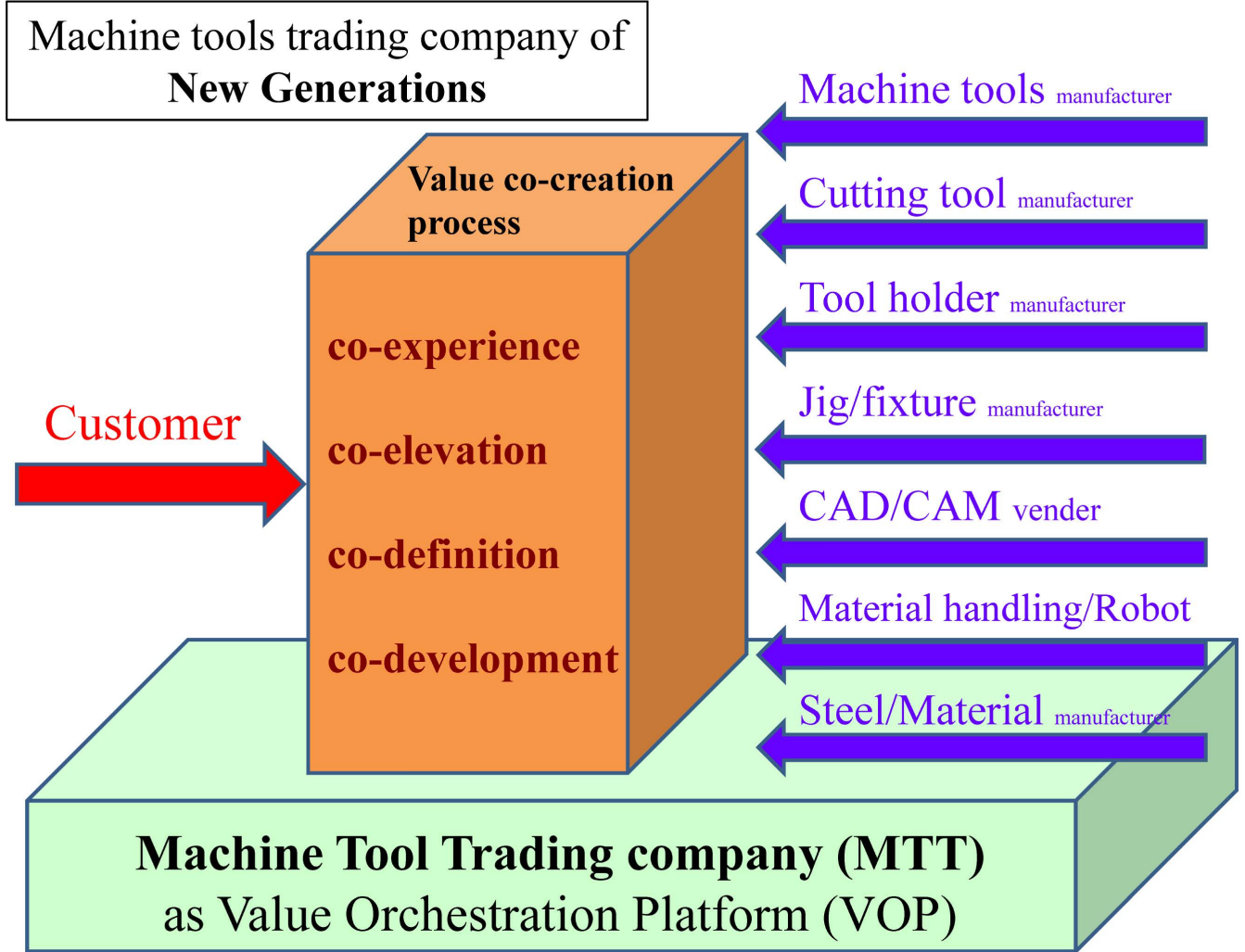

Figure 4. MTT company as value orchestration platform. 
Now let us consider a "recipe" for each strategy for the function of an MTT company as a value orchestration platform. The recipe is based on actual observations and interviews about the state of business in Japan as well as the authors' experiences.

In describing the strategies "QC 7 tools" are very useful, since they can provide an optimal framework for shared understanding as they are generally familiar to machine-tool customers and providers, who are in most cases experienced in QC activities and have been substantially influenced in their conceptual approaches by QC tools [15] [16].

These "QC 7 tools" together comprise a scientific technique that is generally used in each step of quality control, from the identification of a problem to its solution. To these QC 7 tools for quantitative analysis of phenomena, the "new QC 7 tools" are added that are designed for qualitative analysis dealing with linguistic data. They are applied in our investigation of the recipe for realizing a value orchestration platform [15] [16].

\subsection{Segmented Onboard Strategy and Internal Model Fishbone Strategy for Involvement}

We propose the segmented onboard strategy and the internal model fishbone strategy for the co-experience phase. Together, they serve to elucidate and heighten sales skill effectiveness and efficiency by visualizing what has long been implicit knowledge and thus converting it to explicit knowledge [17].

In our discussion of the co-experience phase, we referred to the strategy of drawing customers into the SIPS cycle as the "onboard" strategy (Section 3). We now further propose the addition of QC tool segmentation, to obtain a "segmented onboard" strategy for customer and solution-process segmentation.

It is said that $70 \%$ or more of domestic machine-tool purchasers in Japan are repeat users [18]. Segmentation should include education, enlightenment, and problem solution. Specifically, education involves courses in technology; enlightenment involves new-product exhibitions and courses on new technology, while problem solution involves process demonstration. The service level is serially heightened in the order from education and enlightenment to problem solution. Among the three, education is broadest in reach and most readily draws in customers, and it is therefore well positioned for development of new business.

The fishbone diagram (also known as a characteristic factors diagram and Ishikawa diagram) visualizes the customers' internal model for organization and examination of the constituent elements of that model (Figure 5). The QC perspective is known for its broad " $4 \mathrm{M}$ " classification, using the four main categories of "man" (operator), "material", "machine" and "method" [15] [16].

The three main categories are "tangible", "human", and "intangible", which are further divided into five broad categories with "tangible" comprising "product", "production component”, and "cuttings", "human" comprising "company" and "responsibility", and "intangible" comprising "achievement". Cuttings are the metal waste (chips, shavings, filings, or other waste forms) that occurs in product manufacturing. They provide a ready indication of the quality of the manufacturing process, and have been called "a report card on productivity". Many veteran sales representatives look at process cuttings rather than production components to evaluate the product manufacturing.

The internal model is classified in terms of 26 focal points and described in terms of 60 elements. These numbers may seem large, but veteran sales representatives are deeply familiar with these categories and elements, and in approaching a business negotiation always sets their priorities and develops a success story leading to a contract.

There is currently no existing means of systematizing and visualizing this capability, but if the implicit knowledge of the individual sales representatives were made explicit through visualization by the proposed tools, it could then be used as a checklist. Such a checklist would (1) provide a base for consideration of the strategies to be given in the following subsections, enable an approach to understanding root causes by clarifying the interrelations of the individual elements, and help avoid oversights; (2) help to heighten the capability of the individual sales representatives through explication of that sales representative's implicit knowledge and moreover enable the implementation of a heretofore difficult "team approach" to machine-tool business discussions; and (3) be used as an educational tool for the heretofore difficult process of sales representative education with further progress in implicit knowledge explication.

\subsection{Dynamic Curation Strategy and IP Ethics Strategy for Curation}

We propose two curation strategies; a dynamic curation strategy and an intellectual property (IP) ethics strategy 


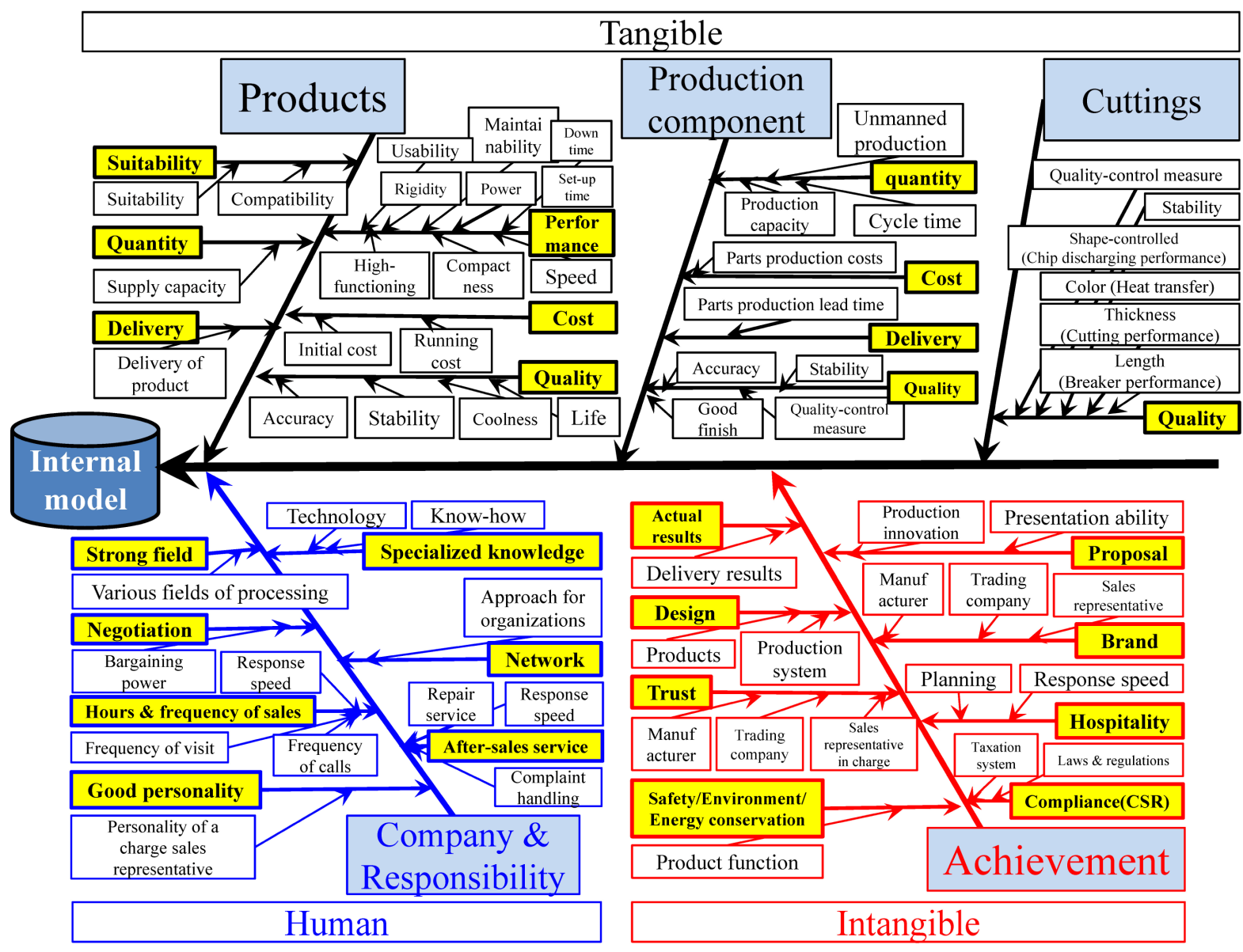

Figure 5. The fishbone diagram.

[19]. The dynamic curation strategy is in particular accord with the longstanding machine-tool business practice of information-priority registration in which the providers who are expected to be onboard change rapidly. The purpose of the IP ethics strategy, which is based on corporate social responsibility (CSR), is to ensure strict observance of confidentiality obligations concerning individual customer's production-technology IP and eliminate the risk of production-technology IP divulgence, a risk that has increased sharply with the modularization of production technology and the high-level digitization of machine technology.

In the transformation of integral skill to modular technology, the number of possible solution combinations tends to increase without limit in successive investigations. The need for an effective dynamic curation strategy is strong and rising. A peripheral equipment provider that has been expected to become an ally at the outset of a business discussion may turn out to be a strong competitive threat after its elimination under the information-priority registration system. The externality effect at the interfaces of an information network may bring onboard a new competitive provider and lead to a new search for a solution matching the customer-specific constraints and conditions of agreement.

These challenges are magnified by the rapid succession of technological advances that emerge almost monthly and could strike a final blow. The adverse effects of technological advances are even stronger than those of networking. Given the singular business practices and the rapid stream of technical innovations, the resources available to the MTT company in its function as a platform may change drastically in the course of a business discussion. A dynamic curation strategy is essential for effective response to this change in resources.

A dynamic curation strategy requires discernment of a story line that includes a time axis for entry of changes in available resources and technical innovations. Here, our analysis is based on the nine constituent elements of the QC story for task achievement [20] which are described as the following: theme selection, procedure selection, point of attack and objective setting, countermeasure proposal, success scenario determination, success 
scenario implementation, confirmation of effectiveness, standardization and control emplacement, and reflection and future response.

In illustration, let us consider a case in which the goal is to increase the level of automated operation and the selected theme is improvement of cuttings disposition. The procedure will depend on whether the target is a machine, a tool, or a material. If a tool is chosen as the target, for example, the procedure begins with consideration of countermeasures development based on analysis of the present state of processing. The point of attack might be tool-type change, cutting conditions, tool path, cutting fluid, or machine-tool specification revision or addition. Let us assume that there are two: change in tool-type and cutting conditions; then the objectives may then be set as cutting conditions and state of cuttings. The countermeasure development and the success scenario will depend in rather large part on the related catalog values, and the cutting test implementation will itself constitute the success scenario implementation and performance of the confirmation step.

An increase in the level of automated operation will require standardization and control emplacement, and a summary outline of each is therefore compiled in sheet form and the circumstances are captured by digital imaging or video. The PDCA cycle is implemented for the reflection and the future countermeasures, as an essential part of QC activity. The control technology as envisioned from thoroughgoing compilation, and pervasiveness of the control sheet is evaluated in the automated process.

The IP ethics strategy is another essential CSR-based curation strategy. When a company repositions its production technology from internal/external integral to internal-modular/external-integral, the technology-bearer center of gravity will shift from human to machine. This facilitates transcription of the technology and enhances its transmissibility within the company, but the attendant speed of propagation with very low attenuation also has the adverse effect of increasing the risk of IP divulgence outside the company.

The core competence of a customer is generally based on a high-level system of production [21], and the obligation for confidentiality in the platform must, as a matter of course, be strictly honored. On the other hand, the curation capability of the MTT company accrues in large part from its acquiring knowledge of the most advanced production lines of its many and various customers. Utilization of a curation capability gained from one customer in a proposal of an advanced production system to another customer is pregnant with the risk of violating an IP right.

In the integral era, it took a long time for a sales representative to gain the capability to reproduce a production technology and obtain an order for a large-scale production system, by which time the sales representative had also received a clear guideline on the obligation to the customer for confidentiality, which obviated problems in platform corporate compliance. In the emerging modular era, in contrast, even a young sales representative lacking any such guideline can reproduce a production technology, though not completely, by combining data on the related process conditions with a specific list from a successful case showing the model numbers of the machine-tool and its peripheral equipment.

No clear legal standard explicating IP rights relating to production technology has yet been established, and it has now become impossible to protect the IP of a customer simply by compliance in the narrow sense of complying with law and regulations. In this light, a clear need has been noted for the development of sincere and faithful corporate culture through promotion of business ethics (i.e., activities for ethical operation) that are the foundation of CSR (Figure 6) [22].

With a shared approach for sincere and faithful operation, corporate ethics can advance the sharing, permeation, and implanting of principles and values, aid the establishment and maintenance of a well-aired corporate structure, and assure implementation of a corporate governance that imbues its personnel with the proclivity for generating and maintaining ethical judgment and behavior.

\subsection{Four Strategies for Empowerment}

Four strategies that are essential constituents of the empowerment strategy are the orchestrator strategy and the objective-function identification strategy in the co-elevation phase, and the relation-matrix strategy and the codesign strategy in the co-development phase.

The orchestrator strategy is directed toward development of the MTT company into a mediator complementing the discontinuous elevation of the service level in the co-elevation phase. The objective-function identification strategy for problem solving narrows the problem from what initially seems to involve many parties to a two-party problem through identification of the objective function. 


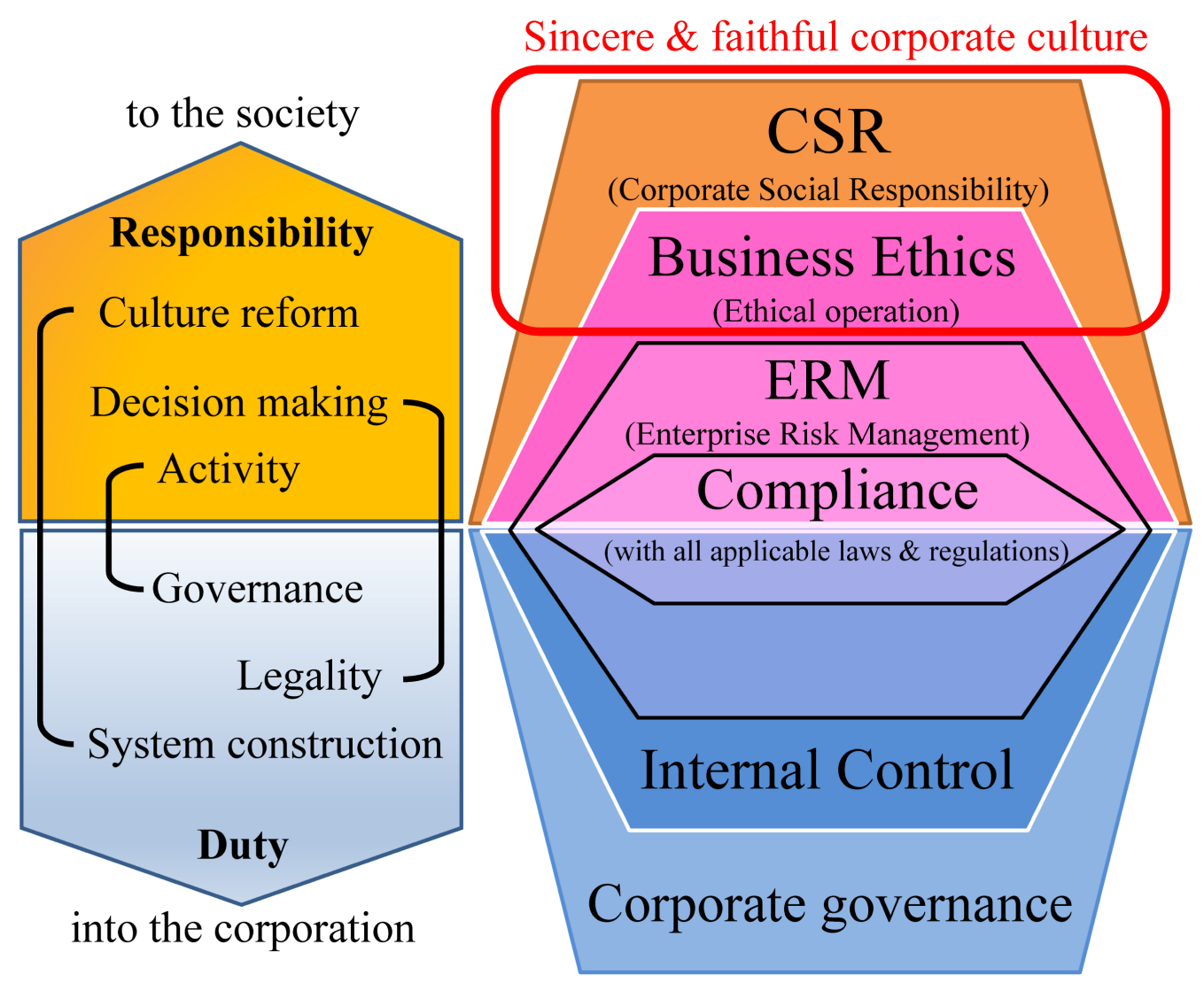

Figure 6. Sincere and faithful corporate culture (Based on [22]).

The relation-matrix strategy is for visualizing and organizing, in the form of a matrix, the interrelations of multiple parties involved in solving a problem, to advance the visualization of solutions to problems in relation to orders of priority and levels of difficulty and to elucidate the leverage points. The fourth strategy is the co-design strategy, which is directed toward manufacturing-site-generated design revision and thus a return to the origin in the recognition that the essence of manufacturing is transcription of design information.

In the co-elevation phase, the process of value co-creation by customers and providers rises in a discontinuous, zigzag spiral. Let us analyze this process using an example in which a machine-tool manufacturer and a cuttingtool manufacturer, i.e., two providers, are striving to raise the level of service (Figure 7). At the time of announcement of a new machine-tool or a new cutting tool, the performance of one may exceed that of the other. Let us assume the performance offered by the machine-tool manufacturer is lower than that offered by the cutting-tool manufacturer. Even though the machine-tool performance has been raised by, say, one rank, the customer's productivity may not rise at all. Raising it by two ranks is then deemed necessary, and the machine-tool manufacturer strives to achieve this increase. If that effort is successful, then it may in response become necessary for the cutting-tool manufacturer to catch up by raising its own product performance by two ranks.

In actual practice, however, this sequence would be exceptional. Following delivery by the manufacturers, they do not ordinarily perform continuing follow-up inspections because of the high cost of performing them at the production site.

An effective solution to this difficulty would be for the customer and the multiple providers to enlist the assistance of a third-party mediator and enter related negotiations [23]. It would, moreover, be most natural for an MTT company to undertake this role as a mediator that would constantly have information on both internal models and new products, and transmit it in both directions. If the mediator had continuously transmitted the internal models to both of the manufacturers in our example, then both might have been able to concurrently offer new products with each raised by two ranks in performance, without incurring the costs of market research. Conversely, if the mediator can sequentially transmit new-product information to the customer, then the customer itself can perform continuous level elevation. As a platform, the MMT company can thus act as though it 


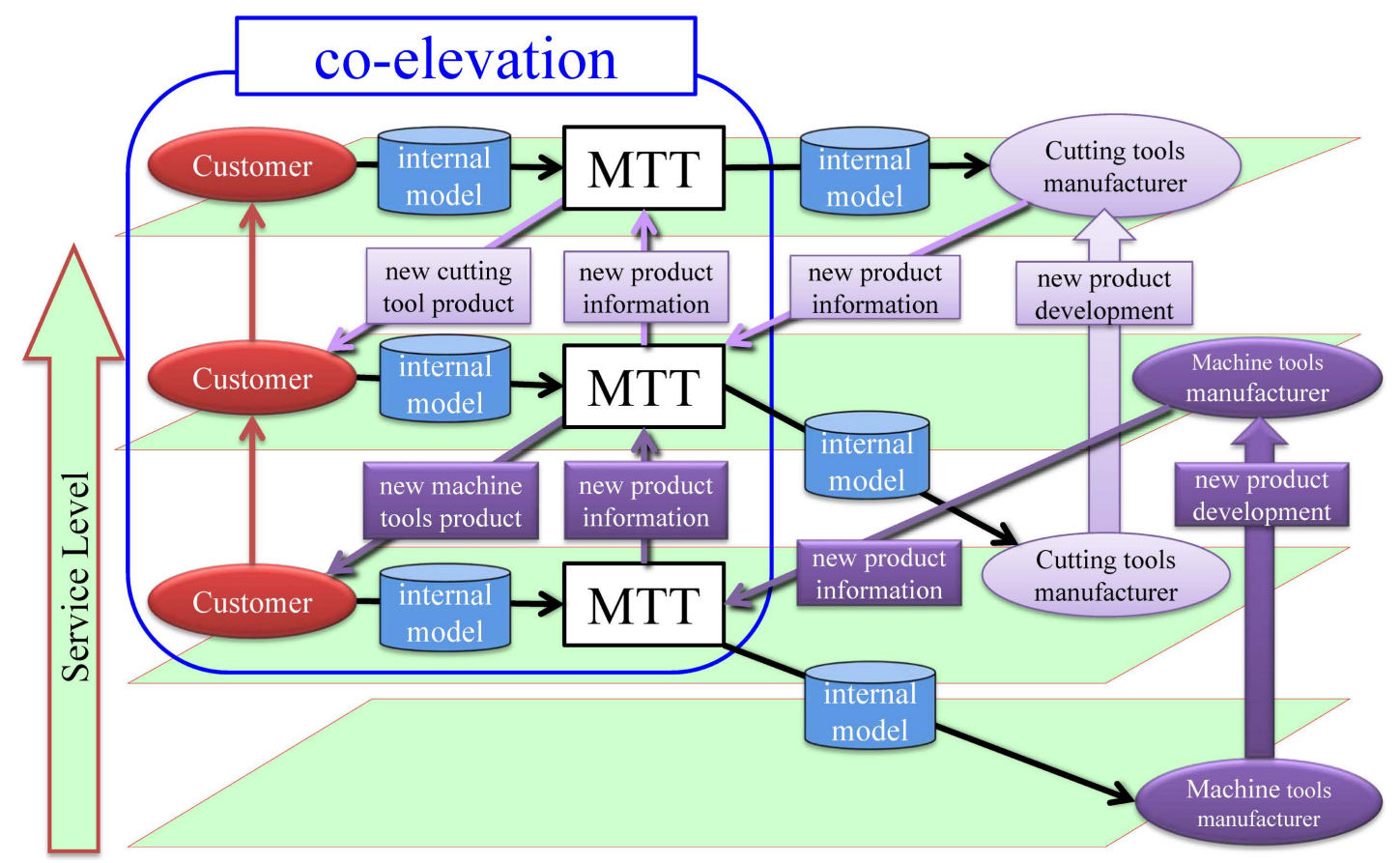

Figure 7. Co-evolution by MTT company.

were a customer to multiple providers and as though it were multiple providers to a customer. This is referred to as the "orchestrator strategy", a name which derives from the name of the platform.

Next let us consider the objective-function identification strategy. Identification of an objective function as a theoretical formula [24] based on the fundamental theory of machine-tool manufacturing can effectively narrow what initially appears to be a multiparty problem to a two-party problem, and thereby facilitate its solution. The objective-function identification strategy can bring actual sales activities, which generally tend to shun theory, back to the basics and increase their efficiency in the process [25]. It can also effectively transform implicit sales skills to explicit sales technology.

A prime example is a theoretical formula for the rate of cuttings generation $Q$, which is an indicator of productivity in turning processes and is formally defined as the quantity of cuttings generated per minute as excess material that is removed to obtain the product in its final geometry. In short, it is an indicator of the number of cubic centimeters discarded per unit time. For increased machining productivity, the objective is accordingly maximization of $Q$, with $Q$ expressed as

$$
Q=V_{c} \times a_{p} \times f_{n}\left(\mathrm{~cm}^{3} / \mathrm{min}\right)
$$

where $V_{c}$ is the cutting speed $(\mathrm{m} / \mathrm{min}), a_{p}$ is the cutting depth $(\mathrm{mm})$, and $f_{n}$ is the feed rate (mm/rev). It is also necessary to include consideration of the machine-tool and cutting-tool constraints in terms of the net cutting power $P_{c}(\mathrm{~kW})$ of the former and the cutting resistance $k_{c}(\mathrm{~N} / \mathrm{mm})$ of the latter [26] [27].

$$
\begin{gathered}
P_{c}=\left(V_{c} \times a_{p} \times f_{n} \times k_{c}\right) /\left(60 \times 10^{3}\right) \\
K_{c}=k_{c 1} \times h_{m}{ }^{-m c} \times\left(1-\left(\gamma_{0} / 100\right)\right)
\end{gathered}
$$

These two equations indicate that for maximization of $Q$ it is desirable to increase $P_{c}$ and decrease $k_{c}$. In most cases, however, $Q$ is maximized first by selecting the maximum feed rate. $F_{n}$, that is, in correspondence with the $\mathrm{a}_{\mathrm{p}}$ matching the cutting tool size, next reducing $k_{c}$, and then by selecting the maximum $V_{c}$ on the power band (the maximum $P_{c}$ region). Narrowing the verification processes to three or four can reduce the number of man-hours that must be redirected form business activities and the cost of test materials to be borne by the customer, and conserve the management resources on the platform. This co-elevation would be difficult to achieve by any other means. 
Let us next consider the two strategies applied in the co-development phase: the relation-matrix strategy and the co-design strategy. The relation-matrix strategy facilitates resolution of the multiparty interrelations involved in co-development by entering them in a matrix diagram, which is a QC tool. Let us here take die machining as an example and analyze its interparty relationships. The customer and all participating providers are entered in the same order on the vertical and horizontal axes of the matrix (Figure 8).

Requests as seen from the perspective of each party shown on a green background in the top row are entered in order from top to bottom for each party. Problems as seen from the perspective of each of the parties are shown on a pink background at the left of the rows. The focal points of human, tangibles, and intangibles from the perspective of curation are distinguished by their colors, with human shown as green, tangibles as yellow, and intangibles as orange.

If a problem is present at symmetric positions (cells framed red in the figure) around the matrix diagonal from upper left to lower right, then it is called a "symmetric problem". In such a case, each related party thinks the other is at fault and therefore expects that party to solve the problem and itself takes no steps for its solution. If the symmetric problem is in the tangible or human category, then a solution can be found through platform mediation. If it is in the intangible category, then it relates to intra-company factors involving design development and IP in both companies, and solution is therefore difficult. In the relation-matrix strategy, the capability for identification and solution of opposing tangibles in symmetric problems is the key.

In an asymmetric problem, the problem resides in one side only. The party in which it resides knows that its solution is beyond the reach of the other party, and in most cases the company with the problem can solve it through its own efforts.

Pinpointing problems in the relation matrix can effectively lead to their identification and solution. For this purpose we leave the parties in the leftmost column as they are, move the problem cells leftward, and place them from left to right in the order of intangible, human, and tangible (Figure 9). The symmetric problems shown here are framed in red.

This procedure is so helpful as to solve problems. Let us here demonstrate its effectiveness with a real case.

In this case, we first took up the asymmetric problems, which are generally relatively easy to solve, and included problems involving perspectives on tangibles, and solved them through curation and negotiation on deli-

\begin{tabular}{|c|c|c|c|c|c|c|c|}
\hline & Customer & $\begin{array}{c}\text { Machine } \\
\text { tool }\end{array}$ & $\begin{array}{c}\text { Cutting } \\
\text { tool }\end{array}$ & $\begin{array}{c}\text { Tool } \\
\text { holder }\end{array}$ & $\begin{array}{c}\text { Jig/ } \\
\text { fixture }\end{array}$ & $\begin{array}{l}\text { CAD } \\
/ \mathrm{CAM}\end{array}$ & $\begin{array}{c}\text { Steel/ } \\
\text { Material }\end{array}$ \\
\hline Customer & & & & & \begin{tabular}{|c|} 
Symmetric】 \\
Design changes \\
to expand the \\
clamp area \\
\end{tabular} & & \\
\hline $\begin{array}{l}\text { Machine } \\
\text { tool }\end{array}$ & & & & & & $\begin{array}{c}\text { Symmetric】 } \\
\text { Dispatch of } \\
\text { programming } \\
\text { instructor } \\
\end{array}$ & \\
\hline $\begin{array}{l}\text { Cutting } \\
\text { tool }\end{array}$ & & $\begin{array}{c}\text { Non-interference } \\
\text { long milling tool } \\
\text { is required. }\end{array}$ & & & $\begin{array}{c}\text { 【Symmetric】 } \\
\text { Non-interference } \\
\text { long milling tool } \\
\text { is required. }\end{array}$ & $\begin{array}{c}\text { 【Symmetric】 } \\
\text { High rotation } \\
\text { tool for medium } \\
\text { load cutting is } \\
\text { required. } \\
\end{array}$ & \\
\hline $\begin{array}{c}\text { Tool } \\
\text { holder }\end{array}$ & & 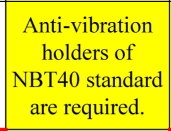 & $\begin{array}{c}\text { Quick delivery } \\
\text { of a wide } \\
\text { variety of } \\
\text { collet }\end{array}$ & & \begin{tabular}{|c|} 
【Symmetric】 \\
Non-interference \\
long holder is \\
required.
\end{tabular} & \begin{tabular}{|c|} 
Non- \\
interference \\
long holders \\
are required. \\
\end{tabular} & \\
\hline $\begin{array}{c}\text { Jig/ } \\
\text { fixture }\end{array}$ & $\begin{array}{c}\text { 【Symmetric】 } \\
\text { Design changes } \\
\text { to increase the } \\
\text { clamping } \\
\text { strength }\end{array}$ & $\begin{array}{c}\text { Specification } \\
\text { change for } \\
\text { allowable } \\
\text { moment }\end{array}$ & \begin{tabular}{|c|} 
【Symmetric】 \\
Specification \\
change of height to \\
non-interference \\
height
\end{tabular} & \begin{tabular}{|c|} 
【Symmetric】 \\
Specification \\
change of height \\
to non-interference \\
height
\end{tabular} & & \begin{tabular}{|} 
【Symmetric】 \\
Specification \\
change of height \\
for non- \\
interference
\end{tabular} & \\
\hline $\begin{array}{l}\text { CAD } \\
/ \mathrm{CAM}\end{array}$ & & \begin{tabular}{|l|} 
【Symmetric】 \\
Short-term \\
debugging
\end{tabular} & \begin{tabular}{|c|} 
【Symmetric】 \\
Tool path \\
optimization for \\
high accuracy and \\
short time
\end{tabular} & & & & \\
\hline $\begin{array}{c}\text { Steel/ } \\
\text { Material }\end{array}$ & & $\begin{array}{l}\text { Quick delivery } \\
\text { of special size } \\
\text { metal material }\end{array}$ & & & & & \\
\hline
\end{tabular}

Figure 8. Relation-matrix. 




Figure 9. Relation-matrix problem pinpointing.

very times and prices for the product to be supplied. The tangible symmetric problems and the human asymmetric problems were similarly solved.

In a case of symmetric problems which on one side was a design improvement problem in the classic human category involving total jig height and on the opposing side was in the tangible category, they were able to have the party with the more-easily solved problem engage in and achieve its solution by procuring a "long cutting tool”, which involved a change in product dimensions. They were then left with the most difficult problem, a symmetric problem in the intangible category. It had reached a deadlock with the customer and the jig manufacturer each seeking to have the other change its design. It was solved through platform concentration on thoroughgoing hearings and mediation between both sides. The customer was also a manufacturer and its technology chief was close to the person holding authority for design changes, which facilitated approval of the related design revision. In the jig manufacturer, the manager and the designer were actually the same person, who was therefore able to make the decision to respond to the customer's new design with a corresponding new design. As a result, it was possible to achieve both a substantial reduction in product cost and a very large increase in product quality.

In this way, the relation matrix can be used for visualization of the relationships based on the fishbone internal modular model with the addition of segmentation performed from the curation perspective, and proceed with the visualization of ordering priorities and levels of difficulty for the problem that is to be solved.

Lastly, let us consider the co-design strategy. Several rounds of experience in value co-creation with strategy analysis using the relation matrix brings a clear, experience-based understanding that the best strategy is "design renewal", which solves problems in intangibles. Many people refer to it as "design change”, but design change is difficult even when the customer itself is a manufacturer, and in many cases a customer involved in processing is actually a collaborating plant.

Design has progressed through various modes, from the era of the manufacturer-centric industrial design conception, through user-centric design and participatory design, to the present focus on co-design in which value co-creation is performed by various types and kinds of individuals at various sites.

In co-design, the producers are brought together by various processes, co-create value together with the customers, and thereby vitalize their sites [28].

Engineers merge with designers, so that the business model moves from product-centric perspective to an eco-system emergence, and the container-like elements undergo a metamorphosis to platforms [29].

In the automotive industry, design-in through simultaneous (or concurrent) engineering has successfully expanded its scope so that it extends from purchasing to upstream processes of design development. Co-design differs from this in several key respects. It involves a substantially larger variety of value co-creation sites. The producer, known as the designer, is an "orchestrator" and the MMT company serves that role. 
For the MTT company co-design is generated on site, but it implements servitization through co-creation that vitalizes customers' production, design and development, purchasing, and services and their related divisions [30] [31]. The goal is evolution to a servitization strategy through provision of a prescription for the co-design strategy.

\subsection{Roadmap for Servitization of MTT Company}

Figure 10 shows a roadmap summarizing the new strategies proposed to this point with the MMT company as a value orchestration platform.

The bottom part of the figure illustrates time frame for the value co-creation process for the MTT company. We suggest an MTT company to involve the customers and providers on board to match them and promote their interaction. Then, they should move to co-experience and co-definition phases, where segmented onboard strategy and internal-model fishbone strategy should be applied. Then they need to step up to co-elevation and codevelopment phases by empowerment strategies. Throughout all the process curation strategies should be crucial for servitization of the MTT company.

The upper part shows how the three attributes of the MTT company will change as the servitization process is going on: while integral technology is transferred to modular technology in the process, accumulation and share of technologies should be essential for ultimate servitization. From the viewpoint of manufacturing capability, servitazaion requires a shift from integrated and operation-oriented organizational capability to integrated production system.

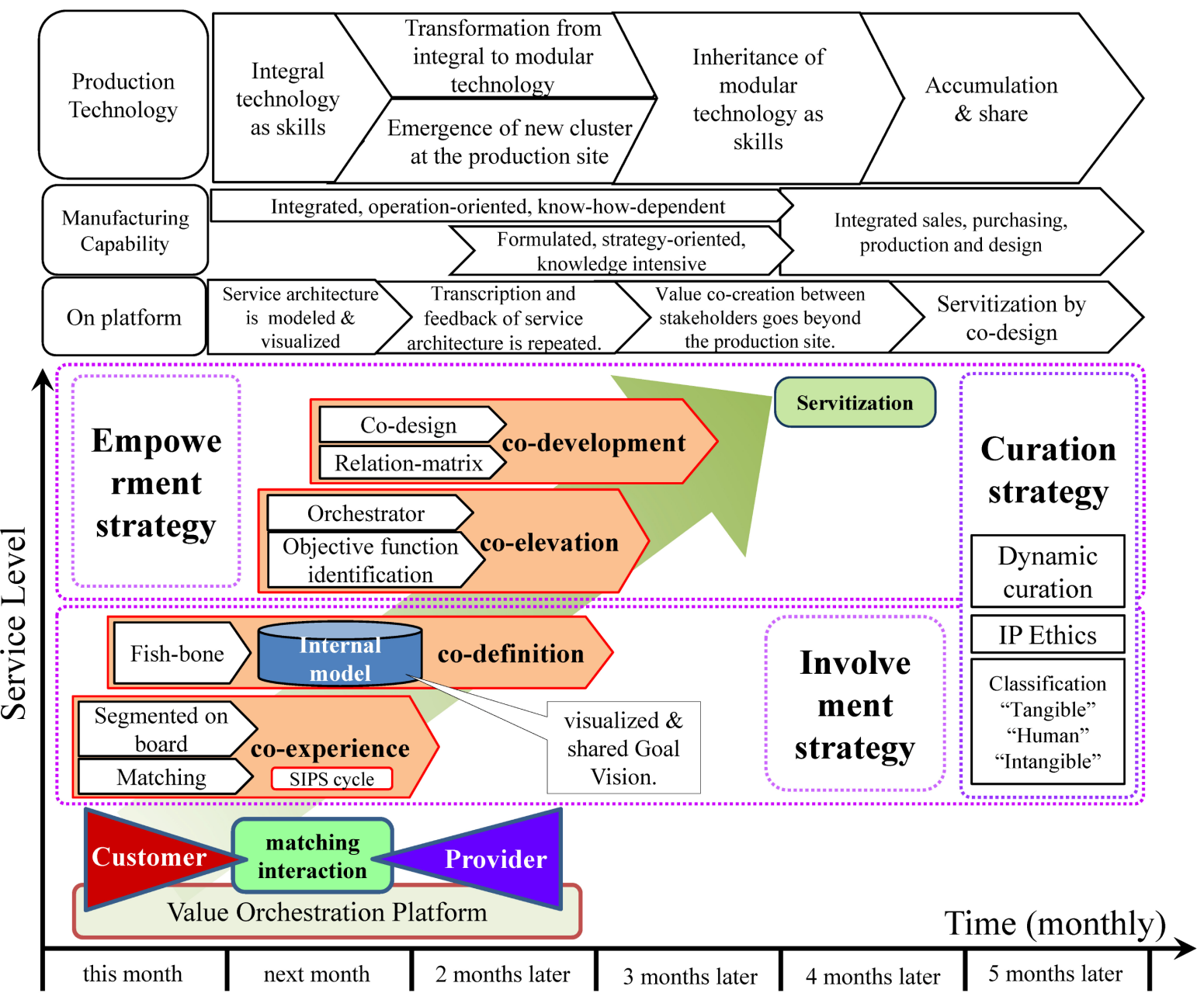

Figure 10. Roadmap for MTT company. 
To implement these processes, the MTT company as value orchestration platform needs to design service architecture, that is, design value to be added through the service.

By using the value orchestration platform model as a reference, it could take the various strategies for involvement, curation and empowerment. These strategies promote value co-creation at the manufacturing site, and it finally leads to servitization not only of the MTT company but also of the participating manufacturing campanies. Through the servitization competitive strength and position of the Japanese manufacturing industry would get recovered.

\section{Conclusions}

In the present paper we first showed the significance and necessity of an innovative modular business model for Japanese manufacturing. Then, we pointed out that for supporting transformation from integral technology to modular technology and their co-existence in manufacturing, machine-tool trading (MTT) companies should play a crucial role in getting servitizatized and functioning as project producers.

After arguing some concrete roles and functions to be expected from servitized MTT companies by using the value orchestration platform model with quality control 7 tools as a reference, we explicated the methodologies, prescriptions and strategies necessary for the implementation in practical terms. These include a segmented onboard strategy, an internal-model fishbone strategy, a dynamic curation strategy (a QC story), an intellectual property (IP) ethics strategy, an orchestrator strategy, an objective-function identification strategy, a relationmatrix strategy, and a co-design strategy.

We concluded with a roadmap for an MTT company to be servitized based on some real observations as well as the authors' experiences.

These arguments demonstrate how these strategies would contribute to the recovery of competitive strength and spur restoration of the competitive position of the Japanese manufacturing industry.

Through visualization of these value orchestration strategies, we were also able to visualize and explicate sales activities, which had generally been largely dependent on the experience and intuition of individuals and thus on implicit knowledge. The visualization and transformation to explicit knowledge of the value co-creation process may be expected to transform machine-tool business discussions from individual play to team play, and by this transformation they facilitate the transmission of sales skills and education to younger sales representatives.

We have analyzed the value orchestration platform strategy in machine-tool transactions. It effectively cast off the traditional shell of captive-party sales restriction. Implementation of the strategy prescriptions contributes to a rise in the contract rate, which has long been difficult to accomplish because of the difficulties involved in concluding agreements for big-ticket modular production systems and to a rising sales trend.

It led to clear and specific expression of increased levels of satisfaction directly from the customers. Furthermore, it confirmed the platform effect of heightening value co-creation. On the other hand, it has also brought substantial concern in regard to the large added workload of monitoring the progress of multiple independent parties, each with its own high-level technology.

Key areas for further study include sales representative development and optimization of the co-design strategy prescription. Education and learning in machine-tool sales skill is increasingly difficult for young sales representatives, who encounter particular difficulty in developing knowledge and expertise in machine-tool engineering, in cutting technology, and in metal materials science, including metallurgy. Research and construction of an effective system for the required human resources development can be accelerated by visualizing the strategy of applying the theories of these three fields of specialization to the process of co-elevation. A second key area for further study is the development of a prescription for the final and best co-design strategy. We believe that one effective approach for this purpose may be to use, for instance, the IP search process of the IPASS matrix [32] in conjunction with the value orchestration platform strategy.

\section{References}

[1] Fujimoto, T. (2013) The Prospects to Manufacturing 2030 in Japan. Harvard Business Review Japan, March. (In Japanese)

[2] Fujimoto, T. (2006) Manufacturing Theory and the Software-From a Viewpoint of Organization Capability and Architecture. Material of the 25th Software Quality Symposium (Union of Japanese Scientists and Engineers), Tokyo, 14-15 September 2006. (In Japanese) http://d.hatena.ne.jp/sessamian/20060917

[3] Baldwin, Y. and Kim, C. (2000) Design Rules: The Power of Modularity. MIT Press, Cambridge. 
[4] Fujimoto, T. (2004) Japanese Manufacturing Industry Strategy and Cooperation between Companies-From a Viewpoint of Organization Capability and Architecture. Document of the 2nd Management Support Sectional Meeting of Ministry of Economy, Trade and Industry, Tokyo, 14 October 2004. (In Japanese) http://www.meti.go.jp/committee/downloadfiles/g41007c40j.pdf

[5] Vargo, S., Maglio, P. and Akaka, M. (2008) On Value and Value Co-Creation: A Service Systems and Service Logic Perspective. European Management Journal, 26, 145-152. http://dx.doi.org/10.1016/j.emj.2008.04.003

[6] Neely, A. (2007) The Servitization of Manufacturing. Proceedings of the 14th EurOMA Conference, Ankara, 17-20 June 2007. http://www.cambridgeservicealliance.org/uploads/downloadfiles/2011-The\%20servitization\%20of\%20manufacturing. pdf

[7] Chino, M. (2010) Does The Problem in 2012 of a Post-Baby Boom Generation Occur? The Bureau of Statistics of the Ministry of Internal Affairs and Communications Website.

[8] Baldwin, Y. and Kim, C. (2004) Modularity in the Design of Complex Engineering Systems. Division of Research, Harvard Business School, Boston.

[9] Kijima, K. (2014) Service Systems Science: Translational and Trans-Disciplinary Approach to Service Systems. In: Kijima, K., Ed., Service Systems Science, Springer, Tokyo, 37-54.

[10] Kijima, K., Rintamaki, T. and Mitronen, L. (2013) Value Orchestration Platform and Value Co-Creation Process: A Hierarchical Service Systems Model and Its Implications. A Presentation at the Naples Forum on Service, Naples.

[11] Toivonen, M. (2004) Expertise as Business: Long-Term Development and Future Prospects of Knowledge-Intensive Business Services (KIBS). Helsinki University of Technology. https://aaltodoc.aalto.fi:443/handle/123456789/2469

[12] Kosaka, M. (2013) Progressive Trends in Knowledge and System-Based Science for Service Innovation. IGI Global, Hershey.

[13] Spohrer, J., Vargo, S.L., Caswell, N. and Maglio, P.P. (2008) The Service System is the Basic Abstraction of Service Science. Proceedings of the 41st Hawaii International Conference on System Sciences, Big Island, 7-10 January 2008, 1-10. http://dx.doi.org/10.1109/hicss.2008.451

[14] Matsushita, H. and Kijima, K. (2014) Value-in-Context of Healthecare: What Human Factors Differentiate Quality of Nursing Service? Service Science, 6, 149-160. http://dx.doi.org/10.1287/serv.2014.0075

[15] Asaka, T. (1980) Quality Control. Japan Standards Association. (In Japanese)

[16] Berger, W. and Benbow, R. (2007) The Certified Quality Engineer Handbook. ASQ Quality Press.

[17] Nonaka, I. and Takeuchi, H. (1995) The Knowledge Creating Company. Oxford University Press, New York.

[18] Mori Seiki Company (2004) Annual Report on Final Accounts of Mori Seiki Co. Ltd. Mori Seiki Co.

[19] Goda, K. and Kijima, K. (2014) Servitization of Machine-Tool Trading Company to Value Orchestration Platform: Japanese Integral-Modular Strategies in Quality Control Perspective. Proceedings of the International Conference of Knowledge and Systems Science, Sapporo, 1-2 November 2014, 161-168.

[20] Kano, N. (1996) Guide to Tqm in Service Industries. Asian Productivity Org.

[21] Prahalad, C. and Hamel, G. (1990) The Core Competence of the Corporation. Harvard Business Review, May-June.

[22] Sanno University (2008) Research Institute-Business Ethics Research Project. "Practice”-Business Ethics and Corporation Compliance. SANNO Institute of Management Publication, October.

[23] Winslade, J. and Monk, G. (2008) Practicing Narrative Mediation. John Wiley \& Sons, Hoboken.

[24] Ito, Y. (2004) Machine Tool Engineering. Corona Publishing, Tokyo. (In Japanese)

[25] Yamane, Y. (2013) Basic Knowledge to Perform the Cutting of Difficulty Cut Materials. Machine Technology. Nikkan Kogyo Shimbun. (In Japanese)

[26] Yokoyama, A. (2012) Basic Knowledge of Steel Materials and the Cutting from the Viewpoint of Elements. Nikkan Kogyo Shimbun. (In Japanese)

[27] Smith, T. (2008) Cutting Tool Technology. Springer Science \& Business Media, London.

[28] Brown, T. (2009) Change by Design. Harper Business, New York.

[29] Ito, J. (2013) Practice of “The Learning” to Begin with Deviation: Change a Town by Power of the Innovation. MIT Media Lab Creative Talk “Learning Creative Learning” Academy Hills Website.

[30] Lai, C. (2010) How to Use the Concept of Servitization of Manufacturing to Increase the Value-Added to Its Product Towards Its Customers. Etd.Lib.Nsysu.Edu.Tw, Kaohsiung.

[31] Ping, W. (2010) Research on Servitization Based on Circulation Economy. Advanced Management Science (ICAMS).

[32] Lee, J. and AbuAli, M. (2011) Innovative Product Advanced Service Systems (I-PASS): Methodology, Tools, and Applications for Dominant Service Design. The International Journal of Advanced Manufacturing Technology, 52, 1161-1173. 